Western University Scholarship@Western

Education Publications

Education Faculty

2017

\title{
Critical Language Awareness
}

Shelley K. Taylor

The University of Western Ontario, tayshelley@gmail.com

Collette Despagne

The University of Western Ontario

Farahnaz Faez

The University of Western Ontario

Follow this and additional works at: https://ir.lib.uwo.ca/edupub

Part of the Education Commons

\section{Citation of this paper:}

Taylor, S. K., Despagne, C., \& Faez, F. (2017). Critical language awareness. In John I. Liontas, Editor in Chief (Project Editor: Margo DelliCarpini; Vol. Ed.: Shahid Abrar-ul-Hassan), The TESOL encyclopedia of English language teaching: Teaching speaking and pronunciation in TESOL. Hoboken, NJ: John Wiley \& Sons. 


\section{Critical Language Awareness}

Shelly K. Taylor, Collette Despagne, AND Farahnaz Faez

\section{Intellectual and Social Context}

In the latter half of the 20th century, applied linguists, dissatisfied with the positioning of language teaching, called for a multidimensional curriculum to reframe teaching (about) languages, be they first or heritage languages (L1s or HLs); English as a second, foreign or international language (ESL, EFL and EIL); or other foreign languages (FLs). Their dissatisfaction stemmed from languages being viewed in isolation (like linguistic silos), an overemphasis on teaching the four skills in a discrete (unintegrated) manner, and decontextualized grammar and vocabulary teaching. Out of this discontent grew the notion of "language awareness," with language awareness pedagogy implemented in the UK school system for the first time in 1974. The notion and pedagogical interventions emerged from the desire to bridge languages taught in isolation, and recognize the role language plays in all subject matter teaching (i.e., language-across-the- curriculum) (Hawkins, 1999).

Later, applied linguists argued that the grammatical and lexical choices authors make in written discourse or other semiotic "texts" are not neutral; their choices can persuade and influence readers of science or business texts just as much as they can shape how polemic arguments are 
interpreted. Researchers advocated for students to be taught how to read texts critically as part of the school curriculum, arguing that they need explicit instruction on how lexical and syntactic maneuvering can position texts as authoritative and thus influence whether EIL students interpret positions and claims as trustworthy and credible (e.g., Clark, Fairclough, Ivanič, \& Martin-Jones, 1991). Students need to be aware that no text is neutral, and that authors can make their points without explicitly revealing their partipris. Applied linguists called for explicit, yet age-appropriate, instruction on critical discourse analysis to equip students with the skills needed to "read" texts critically (including oral, visual, and other texts), and recognize veiled ideologies expressed through seemingly neutral, yet persuasive, lexical choices, phraseology, and symbols. Students able to discern persuasive (not neutral) manifestations of worldviews expressed through vocabulary choices, as well as syntactic and other constructions are deemed to have "critical language awareness" (CLA), or an awareness of "how language conventions and language practices are invested with power relations and ideological processes which people are often unaware of" (Fairclough, 1992/2014, p. 215). 
For EIL students to understand these conventions, practices, relations, and processes, they must first understand worldviews; ideologies; diversity issues involving power, class, gender, race, sexuality; how discussions of language are frequently invisibilized; and, finally, discourse features and techniques. These philosophical, ideological, metalinguistic, and pragmatic issues and topics are not within everyone's ready grasp. Thus, gaining CLA is no easy feat for learners of any age (especially EIL students), and some concepts may even be challenging for teachers. For instance, a CLA perspective may challenge teachers' hitherto unconscious or unproblematized language gap ideologies that stigmatize linguistic minority communities, propagate misconceptions about marginalized communities, and blame EIL students' academic underachievement on "disadvantaged" backgrounds rather than on inequitable power relations; educators may need guidance reflecting on their worldviews, and looking beyond language gap explanations to understanding the mechanisms and outcomes of educational structures (e.g., curriculum, assessment, and pedagogy) that do not meet all students' needs.

In the early days of language awareness, another goal was to counter linguistic prejudices expressed through deficit views of (stigmatized) languages and language varieties (Hawkins, 1999). Though the original and subsequent CLA movements have grown across educational and geographical contexts, stigmatized views of languages and their speakers, 
and a silo approach to language instruction still remain. The term "linguicism" was coined in the 1980s to draw attention to how groups defined themselves or were defined by others on the basis of language (Skutnabb-Kangas, 2015). Speakers of languages described as "superior" gain unequal access to power and resources as a result of ideologies, structures, and practices. Still, language-based racism (linguicism) continues to "hide in plain sight" as manifestations of social practices nestled in, and tied to, power relations. A movement that started as an effort to challenge the "natural" order of conventions, practices, relations, and processes has been taken up by a new generation of researchers dedicated to drawing attention to the role language can play in constructing meanings, how language choices are situated in specific social contexts, and how some of those choices disempower groups of learners (e.g., EIL students).

As linguistic diversity grows across societies as a result of heightened migration, a common question that emerges relates to how to meet the challenge of "managing" diversity. For teachers, the challenge sometimes requires that they play a dual role — as teachers and frontline settlement workers; however, the challenges are no less complex for EIL students in the $\mathrm{K}-16$ classroom or in the professional world. Rather than overcomplicating the conventions, practices, relations, and processes that shape the unsaid, hidden linguistic social order, EIL students and their teachers need to gain awareness of the central tenets of CLA. They need to understand how power 
and ideologies work together to shape linguistic realities (conventions and practices) and, importantly, they need to learn about the transformational promise of CLA; namely, what can be constructed can be deconstructed. Once they come to this realization, it can serve as a resource to help them navigate the changing times and circumstances of power relations. For instance, EIL students and their teachers need to know that "appropriate" grammatical and lexical structures are neither set in stone nor are they the sole property of "L1-speakers," which is itself a contested construct that oversimplifies plurilinguals' competences in multiple languages and language varieties (Faez, 2011). The impact of these realizations is currently felt more in teaching EIL (TEIL) in elementary and adult education than in secondary and higher education, but that gap may yet be filled as views of linguistic conventions and beliefs about discourse and language "ownership" become increasingly critical.

\section{Major Dimensions of Critical Language Awareness}

\section{Critical Language Studies}

At times referred to as critical linguistics, critical discourse analysis, systemic linguistics, linguistic ideology, and some aspects of pragmatics, critical language studies (CLS) are also simply referred to as "language and power," and discussed in terms of relations of power (Fairclough, 
1992/2014). The aim of CLS is to problematize language practices, showing how dominant groups influence social practices (including the establishment of dominant discourse) through "naturalized" conventions. CLS therefore plays a historic function, documenting the imposition of ideologies, but having the potential to also highlight counterhegemonic movements (bottom-up forces) that can usher in social transformation in the micro-context of the classroom, and sometimes also in the macrocontext of broader society. The following are key features of the theoretical claims of CLS. The focus is to explain, rather than merely describe, societal discourse. CLS seeks to illustrate how dominant group members shape conventions underlying accepted (privileged) discourses, and how the naturalized (not 'natural') knowledge that results is not a given; it is reflected in societal practices that change from group to group, and from context to context. CLS also seeks to illustrate how power relations between language users in local-specific contexts determine which language varieties and conventions are deemed (il-)legitimate. The latter designation serves as the subtext behind hidden "grammars," which operate comparably to the "hidden curriculum." Finally, CLS seeks to explain links between conventions that embody ideologies, and how naturalizing conventions also naturalizes ideologies. An analysis of how conventions gain legitimacy reveals the historical context of power shifts between groups (Clark et al., 1991). A CLS approach to EIL is necessary given the 
nature of power differences between the periphery and the center in EIL contexts; differences related to whose varieties of English (or Englishes) are naturalized and deemed (il-)legitimate, and the histories of localspecific experiences related to these power differences (e.g., languageproducer/ language-receiver relationships).

\section{Critical Pedagogy}

A Freirean interpretation of critical pedagogy describes radical pedagogy predicated on solidarity, social responsibility, creativity, and a disciplined approach to working for the common good. It counters views of knowledge as value-neutral and politically neutral, and the assumption that learners are empty vessels into which teachers can deposit dominant group curricular knowledge without paying attention to the prior knowledge students gained in their homes, communities, or life experiences (i.e., the banking model of teaching).

This way of interpreting critical pedagogy also problematizes literacy instruction that fails to draw links between discourse(s), hegemony and the hidden (ideologically laden) curriculum, or to promote critical literacy. The latter entails reading, or making sense of, the word (through decoding text, interpreting it from the perspective of subjectivities gained from one's lived realities, and relating it to personal worldviews), and reading the world (i.e., taking the pulse of the people and communities surrounding oneself, and 
decoding [c]overt, hidden, or tangible but invisible messages in how interactions are shaped). The links between critical pedagogy and CLS are clear. Broadly stated, both instructional approaches favor adopting critical perspectives toward text to uncover underlying messages such as hidden ideological components of curricula or the hidden curriculum (Freire \& Macedo, 1987).

Classroom practices or strategies are needed to enable EIL students and their teachers to recognize that since texts are socially constructed, they can also be deconstructed and rewritten. Classroom practices supporting critical literacy can be developed once EIL students and their educators come to the realization that texts are social constructions that are not neutral. Furthermore, they must understand that authors do not necessarily imagine that diverse audiences will interpret majority discourses differently than planned. Authors may also make (un-)conscious choices when constructing texts either by omitting or silencing particular voices or information, or (re)positioning the representation of constructs through linguistic choices that can only be "seen" if one has knowledge of critical discourse analysis techniques. Once learners and educators have gained critical literacy, they can analyze textual effects on how learners and educators make sense of themselves and others, and read the word and the world (Wink, 2011). 


\section{Critical Literacy}

The fusion of CLS and critical pedagogy occurs in pedagogical practices associated with critical literacy, when critical thinking skills informed by both of the latter are woven into school literacy activities. In the case of reading, a critical literacy approach involves four stages. The first stage involves gaining access to the basic premise of a text and, in the case of EIL students, learning new grammatical and lexical structures while also asking why and how questions, thus making the activity active instead of passive. The second stage draws on students' personal subjectivities to link the text to their everyday literacy experiences, thereby engaging the students in the learning experience (rather than leaving it at an abstract level to which they cannot relate or feel invested). The third, critical, phase goes beyond the personal level, and includes making inferences and problematizing givens; also at this level, educators must raise EIL students' consciousness, alerting them to the need to distinguish between what is stated explicitly (in propositions) as opposed to implicitly (in the hidden curriculum). They need to learn how to read between the lines to identify worldviews and ideologies, their relationship to diversity issues, and the mechanisms of invisibilizing discriminatory language through presenting opinions as facts or with a particular tone. To understand the latter, teachers must scaffold (age-appropriate) activities that enable students to engage in critical discourse analysis. Finally, the creative, emancipatory phase 
transcends metalinguistic awareness, taking critical literacy to the next level whereby EIL students challenge conventions, and engage in some concrete form of action. Seen thus, it is understandable why the scope and nature of language awareness activities would differ significantly from those of critical language awareness activities.

The goal of language awareness is not to attain the emancipatory phase of critical literacy, nor is its mission to challenge the existing social order and seek social justice. That said, EIL students would learn standard English while also learning that their local variety (and other varieties) of English are rich and valid, since that understanding is a key premise of language awareness; however, neither the status quo, nor hierarchical processes of reproduction and legitimation (e.g., English- only policies that do not draw on plurilingualism as a resource for learning EIL) or linguicism would be problematized; neither would discussion center on why some varieties of English seem invisible, why more perks are associated with knowing ("superior") Standard English, or whether Standard English is advantageous in particular fields or discourse communities, and so forth. Finally, it is only CLA's mandate (and not that of traditional non-critical language awareness [LA]) to problematize hidden curricula and grammars and to seize teachable moments by, for example, analyzing how power relations involving race, ethnicity, class, gender, and so on play out in language. The two approaches vary immensely, which has implications for how educators define their roles 
in raising students' (critical) awareness of language.

\section{Educators as Change Agents}

In immigrant-receiving countries in the West, there is a growing discrepancy between teacher and student backgrounds, with primarily White, middle-class female teachers and growing numbers of culturally/linguistically, ethnically, and racially diverse students. Not all teachers, diverse or otherwise, bring inclusive mindsets to the task of educating EIL students. Those who do, may not have the professional knowledge base (e.g., TESOL standards) needed to provide the scaffolding students need to develop critical literacy so may not, for instance, be able to teach them about critical discourse analysis. Even dominant group teachers with inclusive orientations who possess the professional skill-set needed to explicitly teach critical language awareness to EIL students may come across the stumbling block of not sharing their students' authentic, everyday literacy experiences, that is, even well-intentioned, highly skilled, and informed teachers may be unable to connect with EIL students in phase two of critical literacy as their life experiences are so different. Well-intentioned teachers whose personal literacies include White privilege may not understand the impact their EIL students' racial literacies have on these students' critical meta-awareness of hierarchies of power; similarly, monolingual teachers may not understand the complexities of plurilingual 
students' investment in learning EIL within the broader context of their involvement in multiple discourse communities. Therefore, educator mindsets, subjectivities and positioning, familiarity with TESOL standards, and opportunities for meta-reflections are also necessary considerations in whether educators play change agent roles, provide EIL students with explicit instruction on critical language awareness, and implement CLA pedagogy. Though CLA researchers are cognizant of the discrepancies between teacher and learner backgrounds and experiences, they support CLA pedagogies based on a broad spectrum of influences on language and power (race, class, gender, ethnicity, etc.) rather than on a single focus (e.g., racial identities), lest multiple identities be overlooked, groups essentialized, and shared goals unseen or disregarded. The following outlines examples of how the promise of educators as change agents plays out in TEIL contexts in Chile, Mexico, and countries in which minority rights are violated.

Chilean attempts to situate TEIL in a broader, more inclusive understanding of the place of English in a global perspective of languages captures the initial bridging focus of the language awareness movement, but also includes an overtly critical focus. Indigenous languages in Chile, a postcolonial country, enjoy a lower status than European languages (e.g., German and French), and EIL is particularly highly valued. The RECAP (or "Red de Capacitación y Perfeccionamiento para Profesores de Inglés" [Development and learning network for teachers of English]), a consortium 
of higher education institutions aiming to promote high standards of teacher education in TEIL, has explored how to take power relations and social forces into account to change educator attitudes to and beliefs about language learning. RECAP's goal is to move educators along the continuum from decontextualized, overtly grammar orientated pedagogical approaches to TEIL, to the CLA end of the continuum. These approaches focus on the political and societal forces at work in how and which languages are used. RECAP has urged EIL teachers to introduce CLA project work as a means of introducing the following discussion topics: Is Chile a monolingual country? What languages are spoken in Chile other than Spanish, and what is their status? What variety of English do the students speak? Students are also encouraged to explore the implications of the global spread of EIL worldwide and specifically in the Chilean and Latin American contexts, drawing on notions of center and periphery, and analyzing related issues of language and power.

In Mexico, similar, but isolated, attempts to infuse CLA pedagogy into teacher education programs for TEIL have also been introduced. A group of scholars and students at the University of Oaxaca, the most linguistically and culturally diverse state in the country, have explored the roles TEIL educators should play in a multilingual/multicultural context in which indigenous languages are negatively perceived as "dialects," and European languages enjoy "legitimate" (read: real) language status. Their 
work has explored how TEIL teacher educators and pre-service teachers of EIL can apply critical pedagogy in their daily pedagogical practices to create and share power with students; accordingly, their work has focused on topics such as the legitimacy of English, what "legitimate" English language speakers look like, which materials and textbooks can be considered authentic, and issues of bilingualism. For many Mexicans, the goal is to speak "native-like" English, no matter how poorly defined, elusive, or racist that goal may be; however, they face other hurdles as well. Their local knowledges and Englishes are not represented in textbooks, and though many speak an indigenous language, they are not perceived as bilinguals. Teachers wishing to be change agents in that context must tackle ideologies rationalizing historic inequities (i.e., clear cases of linguicism), and face an uphill battle; however, the challenges they face are not as seemingly insurmountable as the ones teachers face in countries that have historically denied the existence of marginalized regional linguistic minority communities, such as the Kurdish minority in Turkey.

As the lines continue to be redrawn in geopolitical areas around the world, the earlier observation that texts socially constructed can also be rewritten holds true. While the challenges facing educators who wish to usher in change may be too great for them to overcome at the present time, individual educators still have some leeway in how they exercise choice and orchestrate classroom interactions. For now, the constraints under which 
some EIL teaching and learning takes place defies implementing CLA practices in ways described above.

\section{Changes Over Time in Critical Language Awareness in TEIL and its}

\section{Treatment}

From initially encouraging explicit attention to issues of power in EIL classrooms such as were evident in genres, discourse conventions, varieties of English, preferred naturalized norms, and so forth, the range of studies claiming to address CLA has expanded (and kept pace with digital innovations such as discourse analysis in Facebook). Increasingly, CLA researchers are urged to look beyond macro issues involving how language and power influence language use (even symbolically), to how to implement CLA-based pedagogy, and to conduct microanalyses involving selecting between languages and language varieties in texts (e.g., codemeshing and other considerations in academic communication and communication with specific discourse communities). Over time, the focus has shifted from teaching grammar all the while remaining cognizant of its grammatical effects, to the pedagogical language knowledge needed by teachers who work with EIL students; knowledge that includes how to engage in "race talk," recognize discriminatory practices designed to remediate presumed language gaps in minority (discourse) communities, understand the value of plurilingualism and dominant and minority group 
students' full linguistic repertoires, and implement translingual pedagogies (Achugar, 2015). There is a growing interest in CLA for EIL students in the literature on English for specific purposes, and applied linguistics for professional practice (e.g., CLA for EIL students learning business English). Recent research has also highlighted connections between student backgrounds and the curriculum, how teachers can increase student collaboration and engagement in the classroom, and the role language ideologies play in the latter. Increasingly, research is linking CLA to how EIL students negotiate their identities in postmodern multilingual contexts, drawing on developments in other social sciences related to theories of social identity for TEIL. These theories adopt poststructuralist approaches to identity whereby identity is regarded as socially constructed, fluid, multiple, dynamic, and subject to change; it is perceived as a collection of roles and subject positions, and a mixture of individual agency and social influences that can be co-constructed and reconstructed through critical pedagogies and critical literacies.

While the general trend in recent years has been for a widening of research on CLA and a broader application of CLA principles to various fields (e.g., applied linguistics across the professions, racial linguistics, etc.), a core group of CLA researchers has cautioned that the net of what qualifies as CLA research should not be cast so widely as to lose sight of its holistic mission (i.e., to heighten awareness of the social and political issues that 
impact language learning and construction).

Current Emphases in Work on Critical Language Awareness in

\section{Research and Theory}

In the four decades since language awareness was introduced to bridge teaching languages and other curricular subjects and to counter linguistic prejudices reflected in deficit views of languages, language varieties, and their speakers, some progress has been made. Inroads have been made into introducing critical literacy into instruction; however, the silo approach to language instruction remains, speakers' background knowledge is still characterized in terms of gaps, and common points of understanding between LA and CLA work require further elaboration. Current research and theoretical emphases in CLA work that show promise include: (a) viewing students' developing EIL as part of their plurilingual development trajectory rather than as fixed competencies, and designing educational spaces for multilingual communication; and (b) infusing teacher-researcher collaborations into teacher education to enhance teacher understanding of CLA and create shared positionalities between teachers and EIL students. 


\section{Designing Space for EIL Students' Plurilingual Development Trajectories}

Conventional wisdom has held that a silo approach to language instruction in which teachers do not allow L1 or other non-target language use in the classroom and orchestrate instruction so that learners presumably only think and interact in the target language (TL) (i.e., EIL) is the best way to teach. Referred to as monolingual ideology, this belief holds that learners' L1s are irrelevant to TL learning (Taylor \& Cutler, 2016). EIL students, however, transcend borders, defying attempts to contain their language development in silos, given their global plurilingual experiences (their dynamic linguistic competences in the language [varieties] in their linguistic repertoires, including incomplete competences in languages important to who they are or may become). Students' dynamic linguistic competences are especially clear in contexts with comprehensive language-in-education policies such as in Singapore's quadrilingual teaching contexts and in the context of, for example, state policy for "tribal" children in the Indian state of Odisha (i.e., mother-tongue based multilingual language education policy for tribal children) that includes four languages: the children's mothertongue (Odia), the state majority language, English and, in later years, Hindi (Mohanty, 2010).

Recently, interest has grown in additive pedagogies embracing EIL students' L1s and the full range of their linguistic repertoires. This interest is 
reflected in new paradigms such as "translanguaging" or "the deployment of a speaker's full linguistic repertoire without regard for watchful adherence to the socially and politically defined boundaries of named... languages" (Otheguy, Garcia \& Reid, 2015, p. 281). Translingual pedagogy reframes schools as spaces for possible plural language practices, thus enacting de facto CLA by challenging established norms and allowing (non-English) voices commonly silenced to be heard. This trend is especially, but not only, evident in multiethnic/multicultural elementary school environments. In higher grade levels, "getting through the curriculum" and "meeting standards" take increasing precedence over holistic views of EIL students. Assessment practices, especially high-stakes EIL tests such as TOEFL and IELTS, which are grammar- and vocabulary-based to a large extent, are intended to measure EIL students' mastery of linguistic norms, standards, and ability to handle academic reading; their ability to critically analyze power relations inherent in genres, discourse conventions, or varieties of EIL are not at issue. Thus, CLA-informed pedagogy in higher education is noteworthy.

English instruction can be built onto other aspects of learners' plurilingual repertoires through code-meshing ("meshing" different languages, and language varieties, together in the same text), a practice that enables EIL students to perform their subjectivities, and/or create stylistic effects, all in the context of a university level L2 writing course. Code- 
meshing, or translanguaging in written texts, raises EIL students' CLA with authorial decisions based on stylistic objectives rather than on accepted grammatical forms and lexical conventions. This translingual practice challenges perceptions of the natural(ized) order all the more as it breaks with written conventions in which languages are kept even more stringently in silos than in speech (i.e., it is more normative). Code-meshers therefore exhibit CLA in consciously crossing boundaries and challenging audiences to accept a new (plurilingual) discourse that may reflect the inadequacy of monolingual knowledge. They accept the consequences of deviating from the norm albeit in a measured way for performative reasons, testing the boundaries between views of (il-)legitimate language, and testing power relations between language users (Canagarajah, 2013).

\section{Collaborative Understanding of CLA and Establishing Commonalities}

One commonality among novice teachers, be they from Denver in the United States, Toronto in Canada, or New Delhi in India, is to identify classroom cultural/linguistic diversity as a major hurdle to successful teaching. The challenges mentioned by novice teachers include: (a) cultural, linguistic, racial, and other mismatches between students and teachers; (b) teacher (mis-) understanding of dominant discourses suggesting that L1 use in the classroom interferes with learning EIL, thereby dissuading teachers from viewing plurilingualism as a resource to learning EIL; and/or (c) 
difficulty understanding CLA informed pedagogy, and how to implement it. Recent research on CLA suggests that teachers from dominant group backgrounds face fewer challenges understanding the value of different varieties of English, including stigmatized varieties, than in understanding power relations due, partly, to their lack of personal experience with various forms of discrimination (e.g., White privilege and, more broadly, racism and linguicism). This research also outlines novel attempts to implement CLA pedagogy through, for example, the use of student journals, text selection for critical reading, theme-focused literacy practica, and drawing on cultural/linguistic practices such as hip hop.

Another thread of recent research relating to teachers' explicit teaching of CLA in the West involves in-service teacher development through collaborative inquiry between teachers and university-based researchers. The purpose is to build teacher capacity, support professional learning and develop teacher-CLA, which can enable teachers to better see and understand learners' multiple knowledges and EIL developmental trajectories. Collaborative inquiry involving two groups of migrant EIL children living in rural settings in the West (Low German-speaking children from Mexico, and L1-speakers of Pennsylvania Dutch), and immigrant children from 50 language groups and 60 different home-countries attending the same school in a major urban city in the West enhanced understanding of: (a) EIL students' plurilingual learning processes, (b) the value of drawing on their 
full linguistic repertoire as a bridge to learning EIL, and (c) the role translanguaging can play in supporting EIL students' learning of other disciplinary subjects. Before accepting the benefits of translanguaging, the teachers had to accept new norms, which then served as counter-discourses to the premises of the monolingual ideology (Stille, Bethke, Bradley-Brown, Giberson, \& Hall, 2016).

Collaborative inquiry also challenges traditional norms by positioning teachers as co-researchers with content-specific wisdom, and as valued contributors to educational reform and transformation by drawing on their emic perspectives. Their involvement in research on EIL from Englishmedium tertiary institutions in Europe and Hong Kong to K-12 settings in the West situates their past practices in relation to norms and conventions, leading to broader discussions of language and power. Teacher involvement in collaborative inquiry on CLA affords them the professional development needed to gain teacher-specific CLA, enabling them to explicitly teach about, and implement, CLA-inspired pedagogy in EIL classrooms.

\section{Future Directions in Research, Theory, and Methodology}

Of the new directions CLA research is taking, three are of particular note. The first relates to continued dissatisfaction with the silo approach to language teaching, the expressed need for bridges, and the original call for 
CLA. These same concerns came to the fore in theoretical reconceptualizations of linguistic competences as dynamic, interrelated systems. The linguistic separation that has long dogged language teaching is referred to as a monolingual teaching paradigm wherein the languages an individual knows, or their linguistic repertoire, is viewed as the sum of separate competences in different languages; a view that influenced how EIL was imagined and taught. With the advances made by psycholinguistic, and sociocultural/sociolinguistic researchers and understanding of the messy, interconnected (shared silo) dimensions of the plurilingual paradigm gaining ground, researchers are designing methodologies to test the limits of its applicability to different contexts of TEIL. As inroads are made, educators begin to valorize the gamut of languages known to individuals, seeing how learners draw on them on an "as needed basis," fulfilling their communicative needs, and how new EIL teaching methodologies give EIL students license to draw on their full linguistic repertoires rather than binding them to conventional boundaries (Otheguy et al., 2015).

It bears noting, however, that while the theoretical advances of the plurilingual paradigm and translingual methodologies speak well to some dimensions of CLA, researchers and educators should not lose sight of its other key dimensions, such as its emancipatory goals. All varieties of EIL may have the same inherent value, but not all languages (or language varieties) are equally supported. TEIL remains a site of negotiation, 
struggle, and resistance. The Council of Europe's (2012) shift from a monolithic linguistic paradigm (and monolingual lens) to a pluralistic paradigm (and intercultural speaker lens), as formalized in its Framework of Reference for Pluralistic Approaches (FREPA), presupposes an ecological space that equally values all languages and identities and views them as resources, which is in keeping with the earlier language awareness movement. The aim is for students to develop sociolinguistic and cultural awareness of the linguistically and culturally diverse societies they live in, understand and respect other perspectives, and be tolerant, curious and open to ambiguity. However, the pedagogical activities that FREPA designed to develop intercultural competence (referred to as "Awakening to languages") neglect CLA's broader mandate, namely, to draw attention to language status, histories, and hierarchies; to stigmatized languages (and speakers); and to why learning EIL is not the same as learning Arabic in France (Despagne, 2013). Future research on TEIL must draw on the promise of the plurilingual paradigm to enable educators to value and draw on their own and their students' full linguistic repertoires. Yet it must also arm them with the CLA necessary to understand how and when sociohistorical positioning and cultural representations constrain their potential, and to mobilize this understanding in order to meet the emancipatory goals of CLA to overcome those constraints; however, how to do so must be the focus of future research, theory, and methodology. 
Critical pedagogy is at the heart of CLA. It is the basis of the notion that the sociocultural capital EIL students gain at home and in the local community fulfills the bridging function between the school curriculum, the micro-level of classroom relations of power, and students' out-of-school knowledge because critical pedagogy starts with what students know. Weaving student expression (voice) and the worldviews gained from their lived experiences into school "texts" provides a counternarrative to normalized (macro) social practices. Students versed in CLA can deconstruct linguistic norms, explicitly discuss and consciously reflect on the legitimacy of the preferred choices of people in power, and choose when to adhere to those choices (norms), and when to challenge them. This knowledge affords them a sense of empowerment. When both educators and students are versed in this knowledge, instruction can be orchestrated around collaborative relations of power, meeting Freirean goals of challenging disabling educational structures to create emancipatory transformations and social change. These processes are best captured by fine-grained ethnographic research lenses that capture the complexity and inherent messiness of EIL students' (digital) identities, linguistic and cultural knowledge bases, and the language choices they make when performing their intersectionality. Ethnographic methods are needed to capture self-reflections, understanding the use (or silencing) of certain discursive features and conventions; they are needed to go beyond broad 
recognition of plurilingualism, varieties, genres, and registers to microaspects of language sometimes referred to as "ideolects" as they are imbued with EIL students' linguistic histories (Otheguy et al., 2015). Increasingly, sociocultural research into critical metalanguage awareness is focusing on practices that transcend narrow conceptions of what counts as language for EIL students in mainstream and FL classrooms, including teacher inquiry into practices that showcase students' multiple identities, languages, and experiences, sometimes through counterhegemonic approaches to vocabulary and grammar that carry more cachet than Standard English in their discourse communities.

An implication for TESOL educators working in EIL, for policy makers who develop standards for EIL, and for teacher educators, is that CLA must be taught in schools for learners and educators to become agents of change. A model for preservice teacher education that would enable future EIL teachers to gain the understanding of CLA needed to introduce it to learners would necessarily touch on topics such as 
1. social awareness of discourse/ideologies (e.g.: How is EIL ideology shaped by, and how does it shape, discourses of globalization and internationalization at the university level? How does this ideology affect relations of power and contribute to their reproduction? While learning EIL enables learners to climb the social ladder in countries such as Mexico, it also contributes to its hegemony. Therefore, what factors go into EIL learners' decisions to learn Standard English in other countries rather than Black English, Singlish, etc.?);

2 critical awareness of diversity (e.g.: Why are some languages/varieties more highly valued than others, and how do they become dominant over time?);

3. consciousness of the need for change, and EIL policies as reflections and sites of social struggles (What are the possibilities and the constraints facing "English+ 1" program initiatives in Europe, dual language education programs in the United States, etc.? How can educators change EIL practices glocally?).

Guidelines for educators with understanding of CLA who wish to explicitly develop EIL students' CLA include: (a) starting with what the students know (grammatical knowledge, and past experiences); (b) scaffolding their attempts to understand and reflect on what is, and imagine what could be; (c) engaging them in age-appropriate critical discourse analysis to understand how language is structured through micro, text-level 
language selections (e.g., which nouns, verbs, adjectives, and allusions does the author use, and what impression does that create?). EIL students must learn to identify, and critique ideological assumptions, and understand how they, their communities, and their society are positioned (Wallace, 2003).

Educators who make EIL students aware of their sociocultural capital and knowledge enable them to develop the self-esteem needed to critically analyze text; develop strategies that challenge linguicist norms, practices, and ideologies that presuppose the superiority of some languages and language varieties over others; and be better positioned to meet academic success. Therefore, CLA must be seen as an essential component of EIL teacher education requirements.

SEE ALSO: Critical Approaches to Second Language Writing; Critical Thinking and Reading; Identity, Voice, and the Second Language Writer; Language Standards in the Classroom; Social Justice 


\section{References}

Achugar, M. (2015). Theme: Critical language awareness approaches in the Americas: Theoretical principles, pedagogical practices and distribution of intellectual labor. Linguistics and Education, 32(Part A), 1-4. doi:10.1016/j.linged.2015.07.003

Canagarajah, S. (2013). Translingual practice: Global Englishes and cosmopolitan relations. New York, NY: Routledge.

Clark, R., Fairclough, N., Ivanič, R., \& Martin-Jones, M. (1991). Critical language awareness Part II: Towards critical alternatives. Language \& Education, 5(1), 41-54. doi:10.1080/ 09500789109541298

Despagne, C. (2013). Review of Klaus Börge Boeckmann, Eija Aalto, Andreas Abel, Tatjana Atanasoska \& Terry Lamb's "Promoting plurilingualism: Majority language in multilingual settings." Graz, Austria: Council of Europe (The European Centre for Modern Languages), 2011. p. 91. TESOL Quarterly, 47(3), 654-7. doi:10.1002/tesq.106

Faez, F. (2011). Reconceptualizing the native/nonnative speaker dichotomy. Journal of Language, Identity and Education, 10(4), 231-49. doi:10.1080/15348458.2011.598127

Fairclough, N. (1992/2014). Critical language awareness (4th ed.). Boston, MA: Addison- Wesley Longman.

Freire, P., \& Macedo, D. (1987). Literacy: Reading the word and the world. 
Westport, CT: Bergin \& Garvey.

Hawkins, E. W. (1999). Foreign language study and language awareness.

Language Awareness, 8(3-4), 124-42.

doi:10.1080/09658419908667124

Mohanty, A. K. (2010). Languages, inequality and marginalization:

Implications of the double divide in Indian multilingualism.

International Journal of the Sociology of Language, 2010(205), 131-

54. doi:10.1515/IJSL.2010.042

Otheguy, R., García, O., \& Reid, W. (2015). Clarifying translanguaging and deconstructing named languages: A perspective from linguistics. Applied Linguistics Review, 6(3), 281-307. doi:10.1515/applirev2015-0014

Skutnabb-Kangas, T. (2015). Linguicism. The Encyclopedia of Applied Linguistics. doi:10.1002/ 9781405198431.wbeal1460

Stille, S. V. V., Bethke, R., Bradley-Brown, J., Giberson, J., \& Hall, G. (2016). Broadening educational practice to include translanguaging: An outcome of educator inquiry into multilingual students' learning needs. Canadian Modern Language Review, 72(4), 476-99. http://dx.doi.org/10.3138/cmlr.3432

Taylor, S. K., \& Cutler, C. (2016). Introduction: Showcasing the translingual SL/FLclassroom: Strategies, practices, and beliefs. Canadian Modern Language Review, 72(4), 389-404. doi:10.3138/CMLR.72.4 
Wallace, C. (2003). Critical reading in language education. New York, NY:

Palgrave Macmillan. Wink, J. (2011). Critical pedagogy: Notes from the real world (4th ed.). Upper Saddle River, NJ: Pearson Education.

\section{Suggested Readings}

Alim, H. S. (2010). Critical language awareness. In N. H. Hornberger \& S. L. McKay (Eds.), Sociolinguistics and language education (pp. 205-31). Tonawanda, NY: Multilingual Matters.

Ranta, L., \& White, J. (2016, July 20). Where are we? Where have we been? Where are we going? Twenty-odd years in the life of Language Awareness. Paper presented at the 13th international conference of the Association for Language Awareness, Vienna, Austria. 